\title{
Thomas Young e a teoria ondulatória da luz no início do século XIX: aspectos conceituais e epistemológicos
}

\author{
Thomas Young and the wave theory of light in the beginning of the $19^{\text {th }}$ century: conceptual and \\ epistemological aspects \\ Rilavia Almeida de Oliveira*回, André Ferrer Pinto Martins ${ }^{1}$, Ana Paula Bispo da Silva² \\ ${ }^{1}$ Universidade Federal do Rio Grande do Norte, Campus Lagoa Nova, Natal, RN, Brasil \\ ${ }^{2}$ Universidade Estadual da Paraiba, Campina Grande, PB, Brasil
}

Recebido em 16 de Maio, 2018. Revisado em 06 de Setembro, 2018. Aceito em 10 de Setembro, 2018.

\begin{abstract}
No ensino de ciências, os relatos acerca de contribuições de personagens importantes da história da física são, por vezes, simplistas, focando apenas em experimentos ditos cruciais ou descobertas pontuais, sem levar em consideração aspectos do contexto em que o pesquisador estava imerso. Esse é o caso da figura de Thomas Young que, em relação à teoria ondulatória da luz, costuma ser associado ao experimento de dupla fenda, na maioria das vezes. Neste trabalho, propomos apresentar, de maneira detalhada, a contribuição dada por Thomas Young para o desenvolvimento da teoria ondulatória da luz dentro do contexto geral da época, com ênfase nos aspectos conceituais e epistemológicos, visando contribuir para a discussão de aspectos da Natureza da Ciência (NDC) no ensino de ciências.
\end{abstract}

Palavras-chave: Natureza da Ciência, Thomas Young, História e Filosofia da Ciência.

In science teaching, reports concerning contributions from important characters in the History of Physics are, most of time, simplistic, focusing only on crucial experiments or specific findings, without considering the aspects of the context in which the researcher was immersed. This is the case of the figure of Thomas Young, who regarding the wave theory of light - is often associated with the double-slit experiment. In this paper, we present, in a detailed way, the contribution given by Thomas Young for the development of the wave theory of light. Considering the general context of the time, we emphasize the conceptual and epistemological aspects, aiming to contribute for the discussion on Nature of Science (NoS) aspects in science teaching.

Keywords: Nature of Science, Thomas Young, History and Philosophy of Science.

\section{Introdução}

A tese de que os estudantes aprendam não somente ciência, mas também sobre a ciência vem se constituindo um tema de pesquisa e atuação no contexto educacional há certo tempo [1,2]. Entende-se que os estudantes devem ter um conhecimento sobre a chamada Natureza da Ciência (NDC), expressão que se tornou bastante conhecida na área de ensino de ciências. Na busca de meios para se contextualizar o ensino e mostrar o processo de transformação da ciência, e em especial da Física, o uso da História e da Filosofia da Ciência (HFC), tem sido indicado como uma estratégia didática que pode trazer benefícios em vários níveis. A pesquisa nesse sentido é ampla, contando com uma vasta bibliografia, tanto nacional quanto internacional [1-3].

Nessa perspectiva de inserção da HFC no ensino de ciências, pesquisadores argumentam que episódios históricos bem explorados permitem uma melhor compreensão da NDC. Episódios históricos cuidadosamente reconstruídos retratam aspectos da NDC em cada contexto

*Endereço de correspondência: rilavia.almeida@gmail.com sócio-histórico-cultural e podem conferir significado a noções epistemológicas abstratas, desvelando os diferentes processos que levaram à construção de conceitos $[4,5]$. Nessa linha, este trabalho aborda os trabalhos de Thomas Young sobre a teoria ondulatória da luz, no início do século XIX, de um ponto de vista conceitual e epistemológico, problematizando o modo como esse episódio histórico pode contribuir para a discussão de temas de NDC no ensino de ciências. A escolha justifica-se pela constatação de que temos poucos trabalhos disponíveis na literatura, em português, que retratam aspectos dos trabalhos de Thomas Young acerca da teoria ondulatória da luz [6-9]. Para realizar esse estudo, utilizamos fontes primárias e secundárias de forma a compreendermos o estudo de caso diacronicamente.

\section{Os trabalhos de Thomas Young sobre a teoria ondulatória da luz}

Ao longo de todo o século XVIII, diferentes concepções concorreram para tentar explicar a natureza da luz. Apesar disso, havia um maior predomínio da teoria corpus- 
cular da luz entre os estudiosos da época, especialmente na Grã-Bretanha. Em fins do século XVIII, contudo, as dificuldades inerentes à teoria corpuscular da luz se tornaram cada vez mais evidentes. A óptica newtoniana e os modelos mecânicos que foram desenvolvidos a partir dela não conseguiam mais explicar os vários fenômenos ópticos conhecidos à época, como, por exemplo, a dupla refração da luz, e um renascimento ou correção da teoria ondulatória estava propenso a ganhar apoio [10]. No início do século XIX, o crescente número de obras baseadas na concepção das ondas deram um grande impulso ao desenvolvimento da teoria ondulatória da luz. Ao longo do século, as teorias ondulatórias da luz ganharam espaço, uma vez que elas poderiam explicar quantitativa e qualitativamente fenômenos ópticos importantes, como: os "anéis de Newton", a polarização e a difração de luz [11].

As pesquisas de Thomas Young (1773-1820) e Augustin Fresnel (1788-1827) sobre difração e interferência lideraram a defesa de uma nova teoria ondulatória da luz, que passou a ser aceita por praticamente todos os estudiosos em torno de 1830, um século após a morte de Newton [12]. Dentro dessas pesquisas, focaremos na discussão dos trabalhos de Thomas Young sobre a teoria ondulatória da luz.

Thomas Young, físico, médico e egiptólogo britânico, nasceu em Milverton, em 13 de junho de 1773. Young estudou medicina em Londres, Edinburgh e Göttingen, entre 1792 e 1799. Seu legado em óptica fisiológica está relacionado a sua formação em medicina. Entre 1791 e 1801, Young publicou a maioria de seus experimentos e teorias sobre óptica fisiológica [13,14].

Em 1800, Young mudou-se de Cambridge para Londres. Nessa cidade, trabalhando como médico, começou a frequentar as reuniões da Royal Society. Young teve contato com Joseph Banks, presidente dessa sociedade, e com Conde Rumford, fundador da Royal Institution. Por indicação deles, em 1801, foi contratado como professor de filosofia natural e editor de publicações da Royal Society. Desta maneira, entre 1802 e 1803 Young preparava aulas populares (Lectures) de filosofia natural e artes mecânicas para os membros da entidade. Estas, consistiam de palestras eruditas que, às vezes, continham resultados de pesquisas recentes. No entanto, eram obscuras, técnicas e muito detalhadas [14].

No início do século XIX, Thomas Young reativou as pesquisas em direção à teoria ondulatória da luð 1 Seu trabalho sobre a teoria ondulatória da luz e sobre o princípio de interferência cobre um período de aproximadamente sete anos, entre 1800 e 1807. Nesse período, Young publicou quatro trabalhos na Philosophical Transactions, que também foram lidos perante a Royal Society de Londres,

\footnotetext{
1 Historiadores, em geral, classificam as teorias do século XVIII como vibracionais e não como ondulatórias, uma vez que estas defendiam a ideia de vibrações através de pulsos de luz [13,21]. Nesse sentido, Thomas Young teria reativado pesquisas ondulatórias que remontam a Christiaan Huygens que, ainda no século XVII, defendia a ideia de ondas na propagação da luz.
}

nos quais discute aspectos sobre os fenômenos da luz. Os quatro trabalhos são: "Outlines of experiments and inquiries respecting sound and light" (carta lida e publicada em janeiro de 1800) [15]; "The Bakerian Lecture: On the Theory of Light and Colours" (lido em novembro de 1801 e publicado em janeiro de 1802) [16]; "An Account of Some Cases of the Production of Colours, not Hitherto Described" (lido em julho de 1802 e publicado em janeiro de 1802) [17]; "The Bakerian Lecture: Experiments and Calculations Relative to Physical Optics" (lido em novembro de 1803 e publicado em janeiro de 1804) [18]. Além desses trabalhos, Young também discute aspectos relacionados à natureza da luz em seu "A Syllabus of a Course of Lectures on Natural and Experimental Philosophy" (publicado em 1802) [19] e também em "A Course of Lectures on Natural Philosophy and The Mechanical Arts" (publicado em 1807) [20].

Em sua teoria sobre a natureza da luz, Thomas Young defendeu a analogia com o som e o papel de um éter ubíqud ${ }^{2}$ Biograficamente, o significado da analogia com o som parece estar relacionado a seu conhecimento em medicina. Suas primeiras pesquisas exploraram os temas de acomodação visual (1793) e acústica (1800), ambas servindo como uma introdução para seu trabalho em óptica física [13].

Na carta lida para a Royal Society em 16 de janeiro de 1800 sob o título "Outlines of experiments and inquiries respecting sound and light", Young discute principalmente sobre o fenômeno do som, mas, também, discute a nova óptica ondulatória, na seção " $X$. A analogia entre luz $e$ som" [15].

Ao discutir a analogia entre luz e som, Young começa citando a grande influência que a teoria corpuscular newtoniana da luz exercia sobre os estudiosos de sua época, afirmando:

Desde a publicação dos escritos incomparáveis de Sir Isaac Newton, sua doutrina de emissão de partículas a partir de luz de substâncias luminosas, e da pré-existência formal de raios coloridos na luz branca, tem sido quase universalmente admitida neste país, e pouco combatida em outros [15, p. 125].

Young, no entanto, traz duas objeções contra a teoria da luz de Newton: a primeira está relacionada com a velocidade uniforme com a qual a luz é suposta ser projetada de todos corpos luminosos, neste sistema, seja devido à fricção de dois cristais ou ao calor intenso do Sol; a segunda diz respeito à dificuldade da teoria newtoniana em explicar a reflexão parcial [15].

Ele defendia que o caráter uniforme da velocidade da luz seria impossível de ser defendido dentro da teoria corpuscular: como poderiam os corpúsculos de luz serem

\footnotetext{
2 O modelo de éter, inicialmente defendido por Young, presumia este constituído de partículas que se repeliam, mas que eram atraídas pela matéria dos corpos. Assim, corpos mais densos possuíam mais éter, ficando rodeados de uma atmosfera etérea [7].
} 
emitidos na mesma velocidade, seja devido à fricção de dois cristais ou ao calor intenso do Sol? Na teoria ondulatória, por outro lado, a velocidade uniforme seria uma característica relacionada ao próprio meio elástico. Young [15] defende que na teoria de Huygens, ao contrário da teoria newtoniana, todas as impressões são transmitidas através de um fluido elástico com a mesma velocidade. Em relação ao fenômeno de reflexão parcial, Young traz que:

Para explicar o fenômeno de reflexão parcial e total, refração, e inflexão, nada mais é necessário que supor todo o meio refrator para reter, por sua atração, uma maior ou menor quantidade de éter luminoso, de modo a tornar sua densidade maior do que a que possui no vácuo, sem aumentar sua elasticidade; e que a luz é uma propagação de um impulso comunicado para este éter por corpos luminosos [...]. Se um corpo elástico menor colide contra um corpo elástico maior, é bem conhecido que o menor é refletido mais ou menos poderosamente, de acordo com a diferença de suas magnitudes: assim, há sempre uma reflexão quando os raios de luz passam de um estrato mais rarefeito a um estrato mais denso de éter; e frequentemente um eco quando um som colide contra uma nuvem. Um corpo maior colidindo com um menor, o impulsiona, sem perder todo o seu movimento: assim, as partículas de um estrato mais denso de éter, não transmitem todo seu movimento ao mais rarefeito, mas, no seu esforço para prosseguir, elas são puxadas pela atração da substância refratora com igual força e assim, a reflexão é sempre secundariamente produzida, quando os raios de luz passam de um estrato mais denso a um mais raro [15, p. $127]$.

No trecho anterior, percebemos que Young aplica o princípio de conservação da quantidade de movimento às partículas de éter, em concordância com o ideal mecanicista de natureza muito influente nesta época. Como salienta Abrantes [22], a partir do século XVII, temos uma forte tendência em se adotar uma imagem mecanicista de natureza na construção de teorias científicas, particularmente no domínio da física.

Young estava familiarizado com as Queries de Newton e com os escritos neo-cartesianos nos quais 'éter' ou 'matéria sutil' servia para unificar vários tipos de fenômenos, incluindo luz, calor, eletricidade, magnetismo, e gravitação. Em sua carta, ele considerou os fenômenos elétricos como uma prova incontestável da existência de um éter, que ele acreditava ser o mesmo éter requerido pela analogia entre som e luz [23].

Ele argumentou que a rápida transmissão de choques elétricos significa que o meio elétrico possui uma elastici- dade tão grande quanto necessária para propagação da luz. No entanto, se o éter elétrico é considerado o mesmo que o éter luminoso, a existência de tal fluido seria, posteriormente, determinada por experimentos [15]. Também argumentou que, assim como som, a luz também tinha pequena tendência a divergir em um meio tão altamente elástico quanto o éter luminoso deveria ser.

Por meio deste argumento, Young buscava ressaltar que a divergência dos raios de luz é imperceptível, objetivando, assim, diminuir o peso da objeção dos corpuscularistas a respeito da teoria ondulatória para a luz, uma vez que corpuscularistas, desde a época de Newton, se baseavam na propagação aparentemente retilínea da luz, para criticar qualquer teoria que defendesse a luz como uma propagação em um determinado meio.

Como podemos perceber, Young busca resolver três grandes objeções à teoria ondulatória: 1) a existência de um éter luminoso no qual esta teoria se baseava, por meio da analogia com os fenômenos elétricos; 2) a velocidade uniforme da luz, uma vez que, como era conhecido, todas as impressões são transmitidas por um fluido elástico com a mesma velocidade; 3) assume que a luz, assim como o som, tinha pequena tendência a divergir, outra grande objeção à teoria ondulatória [14].

Em 1802, Thomas Young publica "On the Theory of Light and Colours $\sqrt{3}[16]$. Esse trabalho começa com quatro hipóteses. As três primeiras procuravam estabelecer a existência de um éter luminífero, no qual ondas eram propagadas quando os corpos se tornavam luminosos, sendo que as diferentes frequências dessas ondas causavam as diferentes cores a serem percebidas na retina $[13,24]$.
Hipótese I: Um Éter luminífero permeia o Universo, altamente rarefeito e elástico. [...] Hipótese II: Ondulações são excitadas neste Éter assim que o Corpo se torna luminoso. [...] Hipótese III: A Sensação de diferentes Cores depende da diferente frequência de Vibrações, excitadas pela luz na Retina [7, p. 7-8].

Em sua quarta hipótese Young afirma:
Hipótese IV: Todos os Corpos materiais têm uma Atração pelo Meio etéreo, através da qual ele é acumulado dentro de suas Substân- cias e por uma pequena Distância ao redor deles, em um Estado de maior Densidade, mas não de maior Elasticidade [7, p. 10].

Young admitiu que os corpos atrairiam éter para si, formando uma atmosfera etérea ao seu redor [7]. Desta maneira, ele poderia explicar fenômenos tais como reflexão e refração, de acordo com a teoria ondulatória. A densidade de éter circundando uma molécula poderia mudar a velocidade da luz passando através desta, causando refração [24]. No entanto, em 1803, Young abandonou essa hipótese de atmosfera de éter.

\footnotetext{
${ }^{3}$ Para estudar esse trabalho de Young utilizamos a tradução em língua portuguesa, disponível em Moura e Boss [7].
} 
Na sequência de seu trabalho, Young traz nove proposições, perpassando a discussão de diferentes aspectos relacionados aos fenômenos luminosos. Entre eles, a velocidade uniforme de um impulso de luz no meio homogêneo (Proposição I); forma esférica das ondulações de luz (Proposição II); propagação retilínea da luz em superfícies concêntricas (Proposição III); reflexão parcial da luz em superfície que limita meios de densidades diferentes (Proposição IV); relação entre o ângulo de incidência e o ângulo de refração na transmissão da luz entre dois meios diferentes e a velocidade de propagação da luz nesses meios (Proposição V); reflexão total da luz (Proposição VI); dispersão da luz (Proposição VII); princípio de interferência (Proposição VIII); e defesa que luz radiante consiste em ondulações do éter luminífero (Proposição IX) [7].

Destacamos a proposição VIII, na qual Young traz uma versão inicial do princípio de interferência:

Quando duas Ondulações, a partir de diferentes origens, coincidem perfeitamente ou quase [coincidem] em Direção, seu efeito conjunto é uma Combinação dos Movimentos pertencentes a cada uma [delas] [7, p. 16].

Young idealizou situações nas quais sua lei de interferência seria aplicada $[23,24]$. Ele traz explicações da aplicação desse princípio nos corolários dessa proposição (Corolário I - Das Cores das Superfícies estriadas; Corolário II - Das Cores dos Filmes Finos; Corolário III - Das Cores dos Filmes Espessos; Corolário IV- Da Escuridão; Corolário V - Das Cores pela Inflexão).

Percebemos, ao longo do tratamento de suas nove proposições, um discurso em favor da teoria ondulatória da luz, procurando minimizar as objeções dos defensores da teoria corpuscular contra a teoria ondulatória.

Entre seus recursos, Young usou o modo newtoniano de exposição: hipóteses e proposições numeradas, com escólios e corolários. Ele também procurou trazer a impressão de concordância com as ideias de Newton, citando extratos de escritos desse estudioso em suporte às suas hipóteses básicas: a existência de um éter elástico impregnando as ondulações causadas por um corpo luminoso e a relação entre cor e frequência. Ele negligenciou a menção que as ondas de éter de Newton eram resultado do impacto dos corpúsculos de luz. Fez cortes constantes nos trechos de Newton, omitindo frases e parágrafos, com o intuito de encaixar as ideias de Newton (que era contrário à teoria ondulatória da luz) com sua argumentação $[7,23,24]$.

Em outro trabalho ("An Account of Some Cases of the Production of Colours, not Hitherto Described"), também publicado na Philosophical Transactions, no ano de 1802, Young inicia defendendo que qualquer que seja a opinião sobre a teoria da luz e das cores que ele havia submetido à Royal Society, deve-se admitir que ela permitiu a descoberta de uma lei simples e geral capaz de explicar uma série de fenômenos de luz colorida que, sem esta lei, permaneceriam inexplicáveis [17]. Nesse estudo, Young apresenta o princípio de interferência como lei, como segue:

Sempre que duas porções da mesma luz atinjam o olho por caminhos diferentes, ambos exatamente ou quase exatamente na mesma direção, a luz torna-se mais intensa quando a diferença de rotas é qualquer múltiplo de um certo comprimento, e menos intensa no estado intermediário das porções em interferência; e este comprimento é diferente para luz de diferentes cores [17, p. 387].

Neste trabalho, Young traz descrições de experimentos envolvendo fibras finas e filmes mistos, buscando corroborar experimentalmente o princípio de interferência. Sobre a formação de franjas produzidas por fibras finas, ele traz a seguinte descrição:

Enquanto eu estava observando a aparência de finas linhas paralelas de luz que são vistas na margem de um objeto preso perto do olho, de modo a interceptar a maior parte da luz de um objeto luminoso distante, e que são produzidas por franjas causadas pela inflexão de luz já conhecida, eu observei que elas são às vezes acompanhadas por franjas coloridas, muito mais largas e mais distintas; e logo encontrei que essas franjas mais largas eram ocasionadas pela interposição acidental de um cabelo. [...] Me ocorreu, que sua causa deve ser procurada na interferência de duas porções de luz, uma refletida da fibra e outra inclinando-se em volta de seu lado oposto [...] $\mathrm{Eu}$, portanto, fiz um orifício retangular em um papelão, e dobrei a sua extremidade de modo a suportar um cabelo paralelo ao lado do orifício: então, colocando o olho próximo ao orifício, o cabelo, obviamente, parece dilatado pela visão indistinta na superfície, a largura era determinada pela distância do cabelo e a magnitude do orifício independentemente da abertura temporária da pupila. Quando o cabelo se aproximou muito próximo a direção da margem de uma vela, que a luz infletida era suficientemente abundante para produzir um efeito sensível, as franjas começam a aparecer e foi fácil estimar a proporção de sua largura com a largura aparente do cabelo, através da imagem da qual eles se estendem [17, p. 388-389].

Em 1804, é publicada outra Bakerian Lecture de Young na Philosophical Transactions, "Experiments and Calculations Relative to Physical Optics" ${ }^{4}$ Este trabalho

\footnotetext{
4 Para Morse [14], nesta conferência Young apresentou a primeira indicação realmente convincente de que as franjas eram produzidas
} 
também é destinado a uma busca de "comprovação" experimental do princípio de interferência, como Young sugere já na primeira seção do trabalho: "I. Demonstração experimental da lei geral de interferência da luz". Nesta, Young afirma que fez experimentos sobre as franjas coloridas acompanhando sombras e encontrou uma prova de que as franjas coloridas são produzidas pela interferência de duas porções de luz [18]. Assim, ele descreve o seguinte experimento:

Eu fiz um pequeno orifício na persiana da janela, e cobri este com um pedaço de papel grosso, que eu perfurei com uma agulha fina. Para maior comodidade de observação, eu coloquei um pequeno espelho sem a persiana da janela, em tal posição de modo a refletir a luz do Sol, na direção aproximadamente horizontal, na parede oposta, e para fazer o cone de luz divergente passar por cima da mesa, onde havia várias telas pequenas de papel cartão. Eu trouxe para o raio do Sol um cartão deslizante, de aproximadamente um trigésimo de uma polegada de largura, e observei sua sombra, seja na parede, ou nos outros cartões mantidos a diferentes distâncias. Além das franjas coloridas em cada lado da sombra, a própria sombra era dividida por franjas paralelas similares, de dimensões menores, diferindo em número, conforme a distância que a franja era observada, mas deixando o meio da sombra sempre branco. Desta maneira, essas franjas eram os efeitos comuns das porções de luz passando em cada lado do cartão deslizante; infletidas, ou melhor difratadas, na sombra. Pois, uma pequena tela sendo colocada a poucas polegadas do cartão, de modo a receber qualquer uma das bordas da sombra na sua margem, todas as franjas que tinham antes sido observadas na sombra na parede imediatamente desapareceram, embora a luz infletida no outro lado pudesse manter seu curso [18, p. 2].

Nas seções seguintes deste trabalho, Young continua defendendo a veracidade de seu princípio, procurando sempre se basear em verificações experimentais. Dessa maneira, ao longo do restante do trabalho, Young traz descrições e resultados de experimentos feitos por ele próprio, bem como compara medidas obtidas em seus experimentos com resultados obtidos por outros estudiosos, a exemplo de Newton. Assim, na sequência, Young: compara medidas deduzidas de vários de seus experimentos com dados obtidos por Newton (Seção II); discute a aplicação do princípio de interferência na formação de arco íris (Seção III); discute a formação de cores a

por interferência. No entanto, Morse argumenta que Fresnel foi o primeiro a elaborar uma explicação física e matemática satisfatória das franjas [14]. partir da transmissão ou reflexão da luz em diferentes objetos (Seção V); procura mostrar que os raios invisíveis existentes além do espectro violeta, que haviam sido detectados por Ritter, também obedeciam à lei geral de interferência (Seção VI) [18].

Na seção IV, a partir das discussões experimentais colocadas, Young propõe uma inferência argumentativa a respeito da natureza da luz:

Desses experimentos e cálculos que tem sido observados, podemos ser autorizados a inferir, que luz homogênea [...] se move mais lentamente em um meio mais denso, que em um meio mais raro; e isto sendo reconhecido, deve ser admitido, que refração não é o efeito de uma força atrativa dirigida para um meio mais denso. Os defensores da hipótese de projétil da luz, devem refletir qual elo de raciocínio eles podem julgar ser o mais fraco nesta sequência; pois, até agora, eu não tinha avançado neste trabalho nenhuma hipótese geral qualquer. Mas, visto que conhecemos que som diverge em superfícies concêntricas, e que som musical consiste em qualidades opostas, capazes de neutralizar uma a outra, sucedendo em certos intervalos iguais, que são diferentes conforme a diferença de nota, estamos totalmente autorizados a concluir que deve haver alguma grande semelhança entre a natureza do som e essa da luz [18, p. 11-12].

O argumento utilizado por Young, no trecho acima, baseia-se no fato de que a luz devia mover-se mais devagar no meio mais denso, o que contrariava o pressuposto usado para explicar a refração na teoria corpuscular. Logo, a luz deveria ser uma ondulação no éter luminoso $[14,23]$. Percebemos, nesse trecho retirado do manuscrito de Young, uma característica sempre presente em seu trabalho: tentar fundamentar sua argumentação sobre a natureza da luz a partir de experimentos, bem como por meio da analogia com o som.

Cabe ressaltar que nestes dois últimos trabalhos Young se concentra na aplicação da lei de interferência a diversos fenômenos, como a formação de franjas resultantes da difração, arco íris, entre outros, procurando mostrar por meio de experimentos a concordância deste princípio com esses diversos fenômenos. Entretanto, algumas vezes Young cita experimentos feitos por outros estudiosos da época, muito embora não os descreva. Young considerava as numerosas e bem-sucedidas aplicações de sua lei de interferência como prova em favor da analogia entre luz e som [23].

Entre os principais aspectos dos trabalhos de Young, podemos concluir que ele: 1) recorre sempre a analogias para explicar os fenômenos luminosos, como a analogia com fluidos, corpos elásticos e, principalmente, a analogia com o som; 2) defende a realização de experimentos para 
corroborar as conjecturas feitas acerca dos fenômenos luminosos; 3) não se utiliza de formulações algébricas, mas utiliza raciocínios geométricos; 4) cita o nome de outros estudiosos, a exemplo de Huygens, Newton e Euler.

\subsection{Repercussões dos trabalhos de Thomas Young}

Em relação à repercussão dos trabalhos de Young, é importante destacar que seus escritos iniciais foram impressos no Philosophical Transactions e também reimpressos no Nicholson's Journal e, com certas modificações, na Lectures [20] [13,23].

A despeito do trabalho de Young, estudiosos da época continuaram a defender a teoria corpuscular. As "ortodoxias metodológicas' $\sqrt{5}$ newtoniana e laplaciana ${ }^{6}$ institucionalmente impregnadas na Grã-Bretanha e na França, respectivamente, tenderam a opor-se à teoria ondulatória. Desta maneira, além da teoria ondulatória proposta por Young ir contra a teoria corpuscular da luz defendida no contexto dessas duas ortodoxias, a hipótese de éter na qual ele sustentava seu trabalho não poderia ser "provada" através de experimentos, principal defesa nessas duas ortodoxias. Como salienta Cantor [13], nesse período havia uma rejeição de fluidos etéreos e, assim, de teorias vibracionais que empregassem o éter luminífero.

O uso de hipóteses também é apontado como tendo contribuído para a rejeição dos trabalhos de Young nesse período. O uso de hipóteses ${ }^{7}$ na construção das teorias científicas era inaceitável para muitos estudiosos da época, especialmente entre os britânicos. No entanto, Young o defendia na produção do conhecimento:

Embora a invenção de hipóteses plausíveis, independentemente de qualquer conexão com observações experimentais, seja de pouco uso para a promoção do conhecimento natural, ainda sim, a descoberta de princípios simples e uniformes, pelos quais um grande número de fenômenos aparentemente heterogêneos são reduzidos a leis universais e coerentes, deve ser sempre admitida como de considerável importância para o aperfeiçoamento do intelecto humano [7, p. 5].

Entre os que criticaram o uso de hipóteses por parte de Young, temos Henry Brougham (1778-1868), um escocês educado em Edinburgh, defensor da teoria corpuscular,

\footnotetext{
5 O programa laplaciano de pesquisa, na França, bem como a ortodoxia newtoniana, entre os britânicos, podem ser caracterizados como ortodoxias metodológicas, uma vez que envolviam a defesa de ideais metodológicos no processo de construção da ciência, em especial, o importante papel atribuído à experimentação no processo de construção do conhecimento.

6 Para melhor entendimento sobre o programa laplaciano de pesquisa dentro do contexto francês, no início do século XIX, consultar Fox [25].

7 Nesta época, entendia-se por 'hipótese' qualquer proposição que fizesse referência a entidades e processos não observados ou qualquer proposição que não pudesse ser verificada por indução.
}

que pertencia a uma escola metodológica que combatia o uso de hipóteses na filosofia natural. Brougham publicou duas revisões dos trabalhos de Young, na Edinburgh Review, nas quais realiza uma crítica argumentando que estes não contém nada que mereça o nome de experimento ou de descoberta, sendo, portanto, destituído de toda espécie de mérito.

Aparentemente, ninguém antes de Fresnel se juntou a Young no estudo dos fenômenos de interferência ou na busca da óptica ondulatória. Entre as razões que têm sido evocadas para explicar essa falta de interesse, Darrigol [23] ressalta o estilo conciso de Young; a fraqueza das explicações teóricas da propagação e refração retilíneas em termos ondulatórios; a disponibilidade da teoria corpuscular para os fenômenos que Young explicou por interferência; bem como o fato de seus contemporâneos terem ignorado a interferência acústica, a partir da qual Young introduziu a interferência óptica.

Em relação ao estilo conciso é necessário destacar que, em seus trabalhos, ao comparar os resultados experimentais de outros estudiosos com os seus, Young, às vezes, não descrevia o experimento a que estava se referindo, deixando alguns pontos obscuros. Sobre essa questão, Morse [14] ressalta que, com frequência, os textos de Young eram prolixos e obscuros e, em outros momentos, concisos a ponto de se tornarem quase incompreensíveis.

Worral [26], no entanto, discorda que o argumento acerca da obscuridade nos trabalhos possa ser usado para justificar o fato da teoria ondulatória de Young não ter conseguido superar a teoria corpuscular predominante entre os estudiosos do período. Segundo Worral [26] o trabalho de Young não era superior à teoria corpuscular predominante no período, e portanto não tinha como superar a teoria corpuscular. Os dois experimentos de Young ditos cruciais (o experimento de dupla fenda, relatado na Lectures [20], e um tipo especial de experimento de difração, descrito na "The Bakerian Lecture: Experiments and Calculations Relative to Physical Optics" [18]) não refutaram a teoria corpuscular, uma vez que esta conseguia trazer explicações, mesmo fazendo uso de hipóteses ad hoc, para os fenômenos envolvidos nos experimentos. Além disso, a teoria ondulatória enfrentava problemas tão grandes (anomalias) como aqueles que a teoria corpuscular enfrentava, a exemplo do fenômeno de dispersão e da dupla refraçãd 8 . Young não ofereceu uma explicação detalhada para esses fenômenos [26].

Além disso, nesses dois experimentos ditos cruciais, Young não traz previsões novas que são confirmadas experimentalmente. No experimento de difração de 1803, ele não previu o espaçamento das franjas de interferência, mas, em vez disso, observou primeiramente as franjas e,

\footnotetext{
8 Sobre dupla refração, Bartholinus, em 1669, tornou-se o primeiro a registrar que um pequeno objeto parece duplo quando visto através de duas faces opostas de um cristal de calcita. Quando um raio incide sobre tal cristal é, em geral, dividido em dois raios refratados. Um desses raios, chamado raio comum, obedece à lei usual de refração, enquanto o outro não e, portanto, é chamado de raio extraordinário [26].
} 
a partir delas, é que calculou os caminhos das porções de luz. Em relação ao experimento de dupla fenda, diversos aspectos da descrição de Young sobre esse experimento indicam que ele nunca o realizou $\sqrt{9}[26]$.

A partir da discussão anterior sobre a recepção dos trabalhos de Young entre seus contemporâneos, constatamos que não há um consenso entre os historiadores quanto aos fatores que contribuíram para um predomínio da teoria corpuscular no meio científico por duas décadas após os trabalhos de Young na teoria ondulatória da luz. Observamos que diversos fatores concorreram para o "fracasso" da teoria ondulatória de Young em superar a teoria corpuscular vigente. Nesse sentido, apesar de reconhecer as deficiências nos trabalhos de Young sobre interferência e difração, salientamos que o contexto predominantemente newtoniano no qual ele escreveu seus trabalhos também não pode ser desconsiderado.

Nos trabalhos de Young sobre os fenômenos luminosos, observamos que, apesar de não defender a teoria corpuscular newtoniana, ele ainda é muito influenciado pelo contexto newtoniano no qual seus estudos se inserem, uma vez que as ideias de Newton ainda eram muito influentes entre os britânicos no início do século XIX. Por exemplo, quanto ao uso da experimentaçã ${ }^{10}$ para corroborar seu princípio de interferência.

No entanto, ele também admitia o uso de hipóteses no processo de construção do conhecimento científico, o que contribui para a rejeição de seu trabalho entre seus contemporâneos, uma vez que estes, educados na tradição newtoniana de não admitir o uso de hipóteses na construção do conhecimento científico, não admitiam a existência do éter.

Por fim, gostaríamos de destacar o fato de Young não trazer desenvolvimentos algébricos em seus trabalhos sobre a natureza da luz. Isso pode ser explicado devido à formação de Young que, como ressalta Morse [14], havia estudado o cálculo das fluxões como autodidata e não tinha habilidade no uso do cálculo diferencial e integral. Vale ressaltar que a aplicação do uso da matemática na solução de problemas físicos não era utilizada, de uma forma em geral, por estudiosos britânicos do período [13].

\section{Implicações para discussões de NDC no ensino de ciências}

O episódio histórico discutido anteriormente mostra-se muito rico do ponto de vista de temas da NDC a serem trabalhados no ensino. Martins [2] propõe trabalhar aspectos da NDC a partir de temas e questões, em vez de princípios de NDC de caráter geral. Tomando como base o trabalho de Driver, Leach, Millar e Scott [27], Martins [2] apresenta os temas a partir de dois eixos principais:

\footnotetext{
9 Para mais detalhes sobre essa questão, consultar Worral [26].

10 Para melhor entendimento sobre o papel da experimentação no contexto científico do século XVIII e início do século XIX, consultar $[13,22]$.
}

[...] o eixo histórico e sociológico e o eixo epistemológico. O primeiro eixo agruparia temas relativos ao papel do indivíduo e da comunidade científica; a intersubjetividade; questões morais, éticas e políticas; influências históricas e sociais; ciência como parte da cultura; comunicação do conhecimento. O segundo eixo, mais amplo, agruparia temas relativos à origem do conhecimento (experiência x razão; papel da observação, da experiência, da lógica e do pensamento teórico; influência da teoria sobre o experimento), aos métodos, práticas, procedimentos e processos da ciência (coleta, análise e avaliação de dados; inferência, correlação e causalidade; modelagem em ciência; papel da imaginação e criatividade; natureza da explicação), e ao conteúdo/natureza do conhecimento produzido (papel de leis e teorias; noção de modelo; semelhanças e diferenças entre ciência e outras formas de conhecimento) $[2, \text { p. } 718]^{11}$

Dentro do eixo sociológico e histórico, poderiam ser discutidos, a partir dos trabalhos de Young sobre a natureza da luz, alguns temas, tais como: 1) papel dos indivíduos/sujeitos e da comunidade científica (influência de outros estudiosos e do newtonianismo no desenvolvimento e na aceitação dos trabalhos de Young); 2) questões morais, éticas e políticas envolvidas (o uso de Young de extratos dos trabalhos de Newton para corroborar sua defesa da teoria ondulatória, sendo que Newton era contrário a esta teoria); 3) controvérsias históricas na ciência (o trabalho de Young é assimilado dentro da controvérsia existente entre teoria corpuscular versus teoria ondulatória da luz, na época de publicação de seus trabalhos); 4) ciência e outros tipos de conhecimento (a relação dos trabalhos de Young sobre teoria ondulatória e sua formação em medicina).

Dentro do eixo epistemológico também podem ser discutidos temas de NDC, por exemplo: 1) o papel das teorias e expectativas preexistentes nas observações e experimentos; 2) o papel dado à experimentação entre os britânicos da época (nos trabalhos de Young sobre a natureza da luz, observamos uma recorrente defesa à experimentação); 3) o papel atribuído ao uso de hipóteses no processo de construção do conhecimento por parte de Young, e sua consequente rejeição entre seus contemporâneos; 4) o papel das analogias na construção da ciência: em seus trabalhos, Young utiliza recorrentemente analogias para explicar diversos fenômenos luminosos (analogia com o som, analogia com fluidos elétricos, analogia com colisões de corpos); 5) os diversos fatores envolvidos na avaliação das teorias científicas (a teoria ondulatória proposta por Young não obteve boa aceitação por parte de seus contemporâneos e diversos fatores concorreram para

11 Para maiores detalhes, consultar tabela 1 constante em Martins [2, p. 719] com exemplos de temas de NDC que podem ser discutidos a partir de cada eixo. 
essa rejeição); 6) o papel atribuído ao uso da matemática no desenvolvimento da ciência, uma vez que Thomas Young não traz desenvolvimentos algébricos em seus estudos sobre a natureza da luz. Desta maneira, pode ser discutida a ideia de que é possível desenvolver conhecimento científico sem o uso de ferramentas matemáticas avançadas; 7) as limitações existentes no conhecimento científico: por exemplo, a falta de uma explicação física plausível para o éter, na época 12 dentre outros.

\section{Considerações Finais}

No estudo do episódio histórico, destacamos os aspectos conceituais e epistemológicos dos trabalhos de Thomas Young, buscando discutir as relações entre os pressupostos epistemológicos sobre a ciência predominantes no início do século XIX e os estudos sobre a natureza da luz neste período.

As discussões contidas nesse episódio histórico podem servir como suporte para trabalhar diversos aspectos sobre a NDC no ensino de ciências, tanto do ponto de vista histórico e sociológico quanto de um ponto de vista epistemológico. O episódio histórico permite, em particular, discutir o papel que as concepções epistemológicas sobre a ciência presentes no contexto em que os estudiosos desenvolvem seus trabalhos científicos exercem no desenvolvimento e aceitação das teorias científicas.

Contudo, cabe ressaltar que os aspectos apontados para a utilização do episódio histórico quanto à NDC não se esgotam aqui. Os temas de NDC dependem, em grande parte, de como o episódio é abordado em sala de aula e da discussão que é promovida.

\section{Referências}

[1] B.A. Moura, Revista Brasileira de História da ciência 7, 32 (2014).

[2] A.F.P. Martins, Caderno Brasileiro de Ensino de Física 32, 703 (2015).

[3] D. Hodson, in: International Handbook of Research in History, Philosophy and Science Teaching, editado por M.R. Matthews (Springer, New York, 2014), p. 911.

[4] R.A. Martins, in: Estudos de história e filosofia das ciências: subsídios para aplicação no ensino, editado por C.C. Silva (Livraria da Física, São Paulo, 2006), p. XXI.

[5] T.C.M. Forato, M. Pietrocola e R.A. Martins, Caderno Brasileiro de Ensino de Física 28, 27 (2011).

[6] T.C.M. Forato, A natureza da ciência como saber escolar: um estudo de caso a partir da história da luz. Tese de Doutorado, Universidade de São Paulo, São Paulo (2009).

[7] B.A. Moura e S.L.B. Boss, Revista Brasileira de Ensino de Física 37, 4203 (2015).

[8] B.V.C. Silva, Latin American Journal of Physics Education 3, 280 (2009).

\footnotetext{
12 O éter permaneceu inexplicável, mas útil, em várias formulações sobre a luz. Ver, por exemplo: Martins [28].
}

[9] B.V.C. Silva e A.F.P Martins, in: Ensino de ciências: relatos de pesquisa e materiais didáticos, editado por T.C.L. Faria e M.G.L. Silva (EDUFRN, Natal, 2009), p. 97.

[10] W. Babcock, British Journal for the History of Science 1, 99 (1962).

[11] C.C. Silva e B.A. Moura, Science \& Education 21, 1317 (2012).

[12] R.A. Martins e C.C. Silva, Revista Brasileira de Ensino de Física 37, 1 (2015).

[13] G.N. Cantor, Optics after Newton - theories of light in Britain and Ireland, 1704-1840 (Manchester University Press, Manchester, 1983).

[14] E.W. Morse, in: Dicionário de biografia científicas, editado por C.C. Gillispie (Contraponto, Rio de Janeiro, 2007), v. 3, p. 2663.

[15] T. Young, Philosophical Transactions 90, 106 (1800).

[16] T. Young, Philosophical Transactions 92, 12 (1802a).

[17] T. Young, Philosophical Transactions 92, 387 (1802b).

[18] T. Young, Philosophical Transactions 94, 1 (1804).

[19] T. Young, A Syllabus of a Course of Lectures on Natural and Experimental Phylosophy (Royal Institution, London, 1802c).

[20] T. Young, A Course of Lectures on Natural Philosophy and Mechanical Arts (Joseph Johnson, London, 1807), v. 2.

[21] B.A. Moura, Scientie Studia 14, 333 (2016).

[22] P.C. Abrantes, Imagens da natureza, imagens da ciência (EdUERJ, Rio de Janeiro, 2016).

[23] O. Darrigol, The history of optics: from Greek antiquity to the nineteenth century (University Press, Oxford, 2012).

[24] F.A.J.L. James, The British Journal for the History of Science 17, 47 (1984).

[25] R. Fox, Historical Studies in the Physical Sciences 4, 89 (1974).

[26] J. Worral, in: Method and appraisal in the physical sciences, editado por C. Howson (Cambridge University Press, Nova York, 1976), p. 107.

[27] R.H. Driver, J. Leach, R. Millar, P. Scott, Young people's images of science (Open University Press, Buckingham, 1996).

[28] R.A. Martins, Caderno Brasileiro de Ensino de Física 29, 52 (2012). 